\title{
Surface Modification of Molybdenum by Iron-Powder Pack Treatment
}

\author{
Yasuhiro Morizono ${ }^{1, *}$, Takateru Yamamuro ${ }^{2}$ and Sadahiro Tsurekawa ${ }^{3}$ \\ ${ }^{1}$ Department of Materials System Engineering, National Institute of Technology, Kurume College, Kurume 830-8555, Japan \\ ${ }^{2}$ Technical Division, Kumamoto University, Kumamoto 860-8555, Japan \\ ${ }^{3}$ Division of Materials Science and Chemistry, Faculty of Advanced Science and Technology, Kumamoto University, \\ Kumamoto 860-8555, Japan
}

Molybdenum sheets were embedded in mixtures of iron, graphite and alumina powders and heated at $1073-1373 \mathrm{~K}$ for $1.8-14.4 \mathrm{ks}$ in a nitrogen flow. This process is a new surface modification technique called "Iron-powder pack (IPP) treatment". The amount of alumina added as an anti-sintering agent was fixed in the powder mixtures, and the volume ratio of iron, graphite and alumina powders was varied from 0:10:2 to $6: 4: 2$. An XRD pattern of the surface of the molybdenum sheet heat-treated at $1273 \mathrm{~K}$ for $3.6 \mathrm{ks}$ using a $0: 10: 2$ mixture had some small peaks for $\alpha-\mathrm{Mo}_{2} \mathrm{C}$. However, it could be identified by optical microscopy and scanning electron microscopy. On the other hand, the use of mixtures containing iron powder led to the formation of an $\alpha-\mathrm{Mo}_{2} \mathrm{C}$ layer. When IPP treatment using a 4:6:2 mixture was carried out at $1273 \mathrm{~K}$ for $3.6 \mathrm{ks}$, the $\alpha-\mathrm{Mo}_{2} \mathrm{C}$ layer with a thickness of approximately $14 \mu \mathrm{m}$ formed on the molybdenum surface. The layer began to be observed at a heating temperature of $1073 \mathrm{~K}$, and grew toward the inside of the molybdenum via the diffusion of carbon from the powder mixture. The sheet covered with the thick $\alpha-\mathrm{Mo}_{2} \mathrm{C}$ layer showed a surface hardness of approximately HV $=1500$. [doi:10.2320/matertrans.MT-M2020177]

(Received June 5, 2020; Accepted July 29, 2020; Published September 25, 2020)

Keywords: molybdenum, iron powder, graphite, alumina, nitrogen gas, carbide formation

\section{Introduction}

Various surface modification techniques, such as plasma nitriding and carburizing, ${ }^{1-5)}$ have been applied to titanium and its alloys to improve their poor wear resistance. Most of the techniques need special equipment and complicated process flows to form a surface hardened layer consisting of titanium nitride (TiN) or carbide (TiC). On the other hand, the authors have recently proposed a simple and easy surface modification technique called "iron-powder pack (IPP) treatment".6,7) In particular, a titanium specimen and a mixture of iron and carbon powders are put in an alumina crucible and heated at $1273 \mathrm{~K}$ for $3.6 \mathrm{ks}$ in a nitrogen flow. During heating, a hardened layer, which has been identified as titanium carbonitride, $\operatorname{Ti}(\mathrm{C}, \mathrm{N})$, forms on the titanium surface. The most important point of IPP treatment is that iron powder is added to the carbon powder. We experimentally confirm that the iron powder has an important role for enhancing the migration of carbon from the powder mixture to the specimen. ${ }^{8)}$

IPP treatment is expected to be available for modification of group 4, 5 and 6 metals, including titanium, vanadium and chromium. Their nitrides and carbides are thermodynamically stable substances and industrially used as a hard member in cutting and drilling tools. To verify the efficacy of IPP treatment for these metals, we selected molybdenum as a metal substrate.

Nitridation and carburization of molybdenum have been investigated by Martinz and Prandini. ${ }^{9)}$ Gas nitriding is carried out at $1073-1473 \mathrm{~K}$ for $72-180 \mathrm{ks}$ in an ammonia atmosphere. Meanwhile, in carburizing, the specimen is fully immersed in a carbon-filled alumina crucible and heated at $1523-1823 \mathrm{~K}$ for $3.6-36 \mathrm{ks}$ in a vacuum of $0.1 \mathrm{~Pa}$. A $\gamma-\mathrm{Mo}_{2} \mathrm{~N}$ layer in the former and an $\alpha-\mathrm{Mo}_{2} \mathrm{C}$ layer in the latter are observed on the molybdenum surface, respectively. Nagae

*Corresponding author, E-mail: morizono@kurume-nct.ac.jp et al. have compared a nitridation phenomenon of molybdenum heat-treated at $1373 \mathrm{~K}$ for $57.6 \mathrm{ks}$ in nitrogen and ammonia atmospheres. ${ }^{10)}$ Although a $\gamma-\mathrm{Mo}_{2} \mathrm{~N}$ layer with a thickness of approximately $80 \mu \mathrm{m}$ is formed in the case of ammonia gas at a pressure of $0.1 \mathrm{MPa}(1 \mathrm{~atm})$, there are no nitrides in the molybdenum substrate heat-treated at nitrogen pressures below $1 \mathrm{MPa}$. In addition, Hoshika et al. have performed carburization of molybdenum at $1773 \mathrm{~K}$ in a vacuum of approximately $0.13 \mathrm{mPa}$ using carbon powder, and have observed an $\alpha-\mathrm{Mo}_{2} \mathrm{C}$ layer on the surface. ${ }^{11)}$

According to these reports, nitridation and carburization of molybdenum is conducted at relatively high temperatures. In IPP treatment, however, the heating temperature is limited because a mixture of iron and carbon powders will melt at temperatures above the eutectic temperature $(1426 \mathrm{~K})$ in the Fe-C binary phase diagram. ${ }^{12}$ ) The purpose of the present study is to examine the effects of the powder composition, heating temperature and holding time on the microstructures and hardness in the vicinity of the surface of molybdenum subjected to IPP treatment, and to discuss its effectiveness as a surface modification technique.

\section{Experimental Procedures}

A commercially pure molybdenum sheet with a purity of $99.95 \mathrm{mass} \%$ and a thickness of $0.1 \mathrm{~mm}$ was used as a substrate. The sheet was cut into $10 \mathrm{~mm} \times 10 \mathrm{~mm}$ squares. Since the sheet was too thin, mechanical grinding for its surface was not carried out. The surface keeping a purchased state was sheeny. Before IPP treatment, the sheet was degreased in acetone using an ultrasonic cleaner and dried with hot air.

Mixtures of commercially available iron, graphite and alumina powders were put into an alumina crucible, and molybdenum sheets were embedded in the mixtures. The iron, graphite and alumina powders were the same as those in our previous study. ${ }^{6}$ Carbonyl iron was used as an iron 
Table 1 Volume ratio of iron, graphite and alumina powders used in IPP treatment.

\begin{tabular}{|c|c|c|c|}
\hline \multicolumn{3}{|c|}{ Powder mixtures (Volume ratio) } & \multirow{2}{*}{$\frac{\mathrm{Fe}}{\mathrm{Fe}+\mathrm{C}+\mathrm{Al}_{2} \mathrm{O}_{3}}$} \\
\hline Iron $(\mathrm{Fe})$ & Graphite (C) & $\begin{array}{c}\text { Alumina } \\
\left(\mathrm{Al}_{2} \mathrm{O}_{3}\right)\end{array}$ & \\
\hline 0 & 10 & 2 & 0 \\
\hline 2 & 8 & 2 & 0.17 \\
\hline 4 & 6 & 2 & 0.33 \\
\hline 6 & 4 & 2 & 0.50 \\
\hline
\end{tabular}

powder. It was fine and spherical (particle size, $D_{50}=3.9$ $5.2 \mu \mathrm{m})$, and contained $0.75-0.90$ mass $\%$ C, $0.65-0.90$ mass $\% \mathrm{~N}$, and $0.15-0.40$ mass $\%$ O. The graphite powder with a particle size of approximately $24 \mu \mathrm{m}$ was added as a carbon source. On the other hand, the alumina powder assumed the role of an anti-sintering agent and the particle size was approximately $2 \mu \mathrm{m}$. Table 1 shows the volume ratio of iron, graphite and alumina powders in the mixtures. Each powder was added to a graduated measuring glass by tapping until the necessary volume was obtained, and then the iron, graphite and alumina powders were carefully mixed in a beaker. Approximately $8 \mathrm{~mL}$ of the powder mixture was put in the crucible.

The crucible, which was filled with the molybdenum sheets and the powder mixture, was placed in a horizontal heat treatment furnace connected with a rotary vacuum pump and a nitrogen gas cylinder. The furnace was also used in the previous studies. ${ }^{6-8)}$ After repeatedly evacuating the furnace using the rotary vacuum pump and refilling it with nitrogen gas a few times, the crucible was heated in the temperature range of $1073-1373 \mathrm{~K}$ for $1.8-14.4 \mathrm{ks}$ in a nitrogen flow. The nitrogen gas had a purity of $>99.99 \mathrm{vol} \%$, and it flow rate was $500 \mathrm{~mL} / \mathrm{min}$. All specimens were allowed to cool in the furnace to room temperature. In some cases, a detector of carbon monoxide (CO) gas was attached to a gas exhaust port in the furnace, and its concentration was monitored during IPP treatment.

After IPP treatment, X-ray diffraction (XRD) measurements, scanning electron microscopic (SEM) observations and Vickers hardness tests were performed on the surface of the molybdenum sheets. XRD measurements with $\mathrm{Cu} \mathrm{K} \alpha$ radiation were conducted at a tube voltage of $40 \mathrm{kV}$ and a tube current of $40 \mathrm{~mA}$. The accelerating voltage during SEM observations was $15 \mathrm{kV}$. In the hardness tests, a load of $2.94 \mathrm{~N}$ was applied at room temperature for $15 \mathrm{~s}$. Thereafter, the sheets were mounted in an electrically conductive resin and cut in half. To reveal the microstructures, the cross sections were ground with waterproof abrasive papers and then mirror-finished by using a diamond slurry with a particle size of $0.5 \mu \mathrm{m}$. The microstructures were examined by using optical microscopy, SEM, and electron probe X-ray microanalysis (EPMA, accelerating voltage: $15 \mathrm{kV}$ ). Before optical microscopy and SEM, the specimens were etched in an aqueous solution containing potassium ferricyanide and potassium hydroxide $\left(\mathrm{K}_{3}\left[\mathrm{Fe}(\mathrm{CN})_{6}\right]\right.$ : $5 \mathrm{~g}, \mathrm{KOH}: 5 \mathrm{~g}, \mathrm{H}_{2} \mathrm{O}$ : $100 \mathrm{~mL})$.

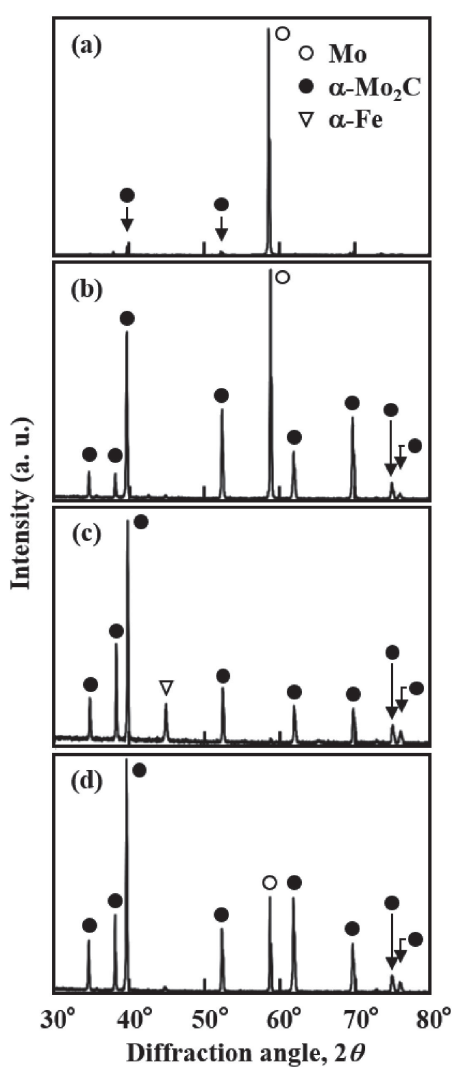

Fig. 1 XRD patterns of the surface of a molybdenum sheet heat-treated at $1273 \mathrm{~K}$ for $3.6 \mathrm{ks}$ in a nitrogen flow using various powder mixtures. Iron:graphite:alumina $=$ (a) 0:10:2, (b) 2:8:2, (c) 4:6:2, and (d) 6:4:2.

\section{Results and Discussion}

\subsection{Optimum powder composition for IPP treatment}

Figure 1 shows XRD patterns of the surface of a molybdenum sheet heat-treated at $1273 \mathrm{~K}$ for $3.6 \mathrm{ks}$ in a nitrogen flow using various mixtures of iron, graphite and alumina powders. As shown in Fig. 1(a), when a mixture without iron powder was used, diffraction peaks for not only molybdenum but also $\alpha-\mathrm{Mo}_{2} \mathrm{C}$ were observed. The formation of $\alpha-\mathrm{Mo}_{2} \mathrm{C}$ suggests a chemical reaction between graphite and molybdenum during heating. However, the peaks for $\alpha-\mathrm{Mo}_{2} \mathrm{C}$ were too small, and it could not be identified by optical microscopy and SEM. On the other hand, there were intense peaks corresponding to $\alpha-\mathrm{Mo}_{2} \mathrm{C}$ in Figs. 1(b) to (d), when mixtures with iron powder were used. An $\alpha$-iron peak in Fig. 1(c) also arose from the iron powder adhering to the surface of the specimen.

Vickers hardness tests were conducted for the specimens shown in Fig. 1, and the results are presented in Fig. 2. The measurements were carried out 5 times of each specimen, and the mean value and standard deviation were calculated. The horizontal axis in the figure is the $\mathrm{Fe} /\left(\mathrm{Fe}+\mathrm{C}+\mathrm{Al}_{2} \mathrm{O}_{3}\right)$ ratio in Table 1, and the dashed line denotes the surface hardness of an untreated molybdenum sheet. As the amount of the iron powder in the mixture was increased, the molybdenum surface subjected to IPP treatment was gradually hardened. The highest hardness was obtained by using a 4:6:2 mixture of iron, graphite and alumina powders $[\mathrm{Fe} /(\mathrm{Fe}+\mathrm{C}+$ $\left.\mathrm{Al}_{2} \mathrm{O}_{3}\right)=0.33$ ]. Figure 3 shows an optical micrograph of the cross section of the molybdenum sheet heat-treated at 


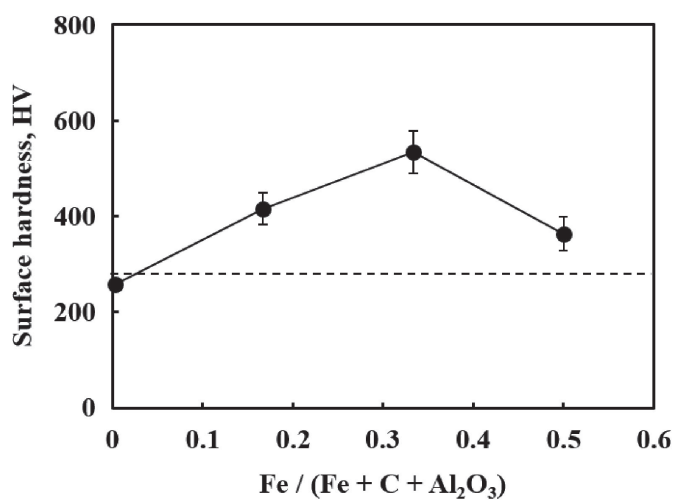

Fig. 2 Surface hardness of a molybdenum sheet heat-treated at $1273 \mathrm{~K}$ for $3.6 \mathrm{ks}$ in a nitrogen flow using various powder mixtures. The horizontal axis is the $\mathrm{Fe} /\left(\mathrm{Fe}+\mathrm{C}+\mathrm{Al}_{2} \mathrm{O}_{3}\right)$ ratio in Table 1 , and the dashed line represents the average surface hardness of the sheet before heat treatment.

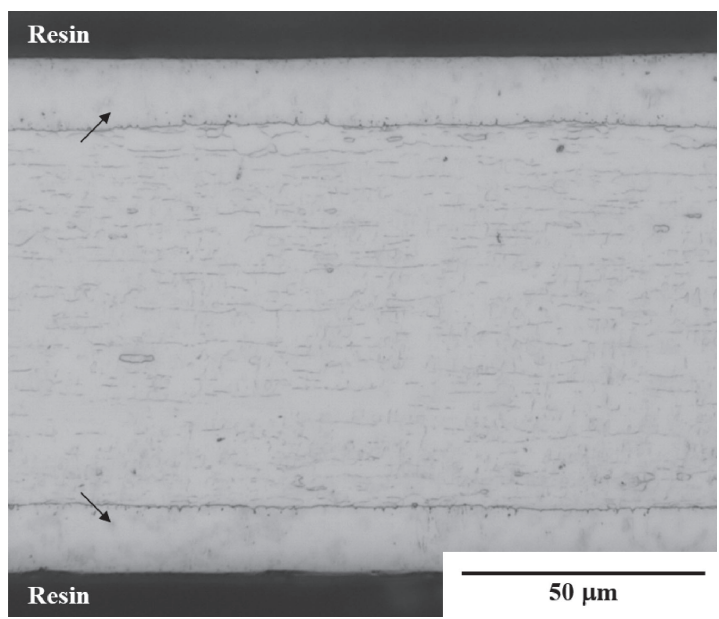

Fig. 3 Optical micrograph of a cross section of a molybdenum sheet heattreated at $1273 \mathrm{~K}$ for $3.6 \mathrm{ks}$ in a nitrogen flow using a 4:6:2 mixture of iron, graphite and alumina powders.
$1273 \mathrm{~K}$ for $3.6 \mathrm{ks}$ in a nitrogen flow using the 4:6:2 mixture. There was a continuous reaction layer on both sides of the sheet, as indicated by the black arrow. On the basis of the XRD pattern in Fig. 1(c) and the results of elemental mapping shown in Fig. 4, the layer was determined to be $\alpha-\mathrm{Mo}_{2} \mathrm{C}$. Although the thickness of the $\alpha-\mathrm{Mo}_{2} \mathrm{C}$ layer was approximately $14 \mu \mathrm{m}$, the hardness value in Fig. 2 was unexpectedly small. As we will describe later, the reason is because Vickers hardness tests were carried out under a test load of $2.94 \mathrm{~N}$ and the measurement values were affected by the molybdenum substrate.

The average chemical composition of the $\alpha-\mathrm{Mo}_{2} \mathrm{C}$ layer, which was formed on the molybdenum surface by IPP treatment at $1273 \mathrm{~K}$ for $3.6 \mathrm{ks}$ in a nitrogen flow using the 4:6:2 mixture, was quantitatively determined by using EPMA to be $63.7 \mathrm{~mol} \% \mathrm{Mo}, 35.1 \mathrm{~mol} \% \mathrm{C}$ and $1.2 \mathrm{~mol} \%$ Fe. Compared to the Mo-C binary phase diagram, ${ }^{13)}$ the measured concentration of carbon was slightly high. This may be due to contamination of the area during analysis. In addition, the existence of iron in the layer indicates contact between iron powder and molybdenum during IPP treatment. On the other hand, nitrogen was not detected in the sheet by EPMA analysis, although IPP treatment was conducted in a nitrogen atmosphere. Even in Fig. 1, there were no diffraction peaks for molybdenum nitrides like $\mathrm{Mo}_{2} \mathrm{~N}$. As mentioned in the introduction, it has been pointed out that nitridation of molybdenum in nitrogen gas is difficult. ${ }^{10)}$ Consequently, molybdenum preferentially reacted with carbon via IPP treatment.

Figure 5 shows the relationship between the thickness of the $\alpha-\mathrm{Mo}_{2} \mathrm{C}$ layer and the composition of powder mixtures used in IPP treatment at $1273 \mathrm{~K}$ for $3.6 \mathrm{ks}$ in a nitrogen flow. The horizontal axis is represented as the $\mathrm{Fe} /(\mathrm{Fe}+\mathrm{C}+$ $\mathrm{Al}_{2} \mathrm{O}_{3}$ ) ratio in Table 1. The thickness of the $\alpha-\mathrm{Mo}_{2} \mathrm{C}$ layer increased with an increase in the amount of the iron powder,
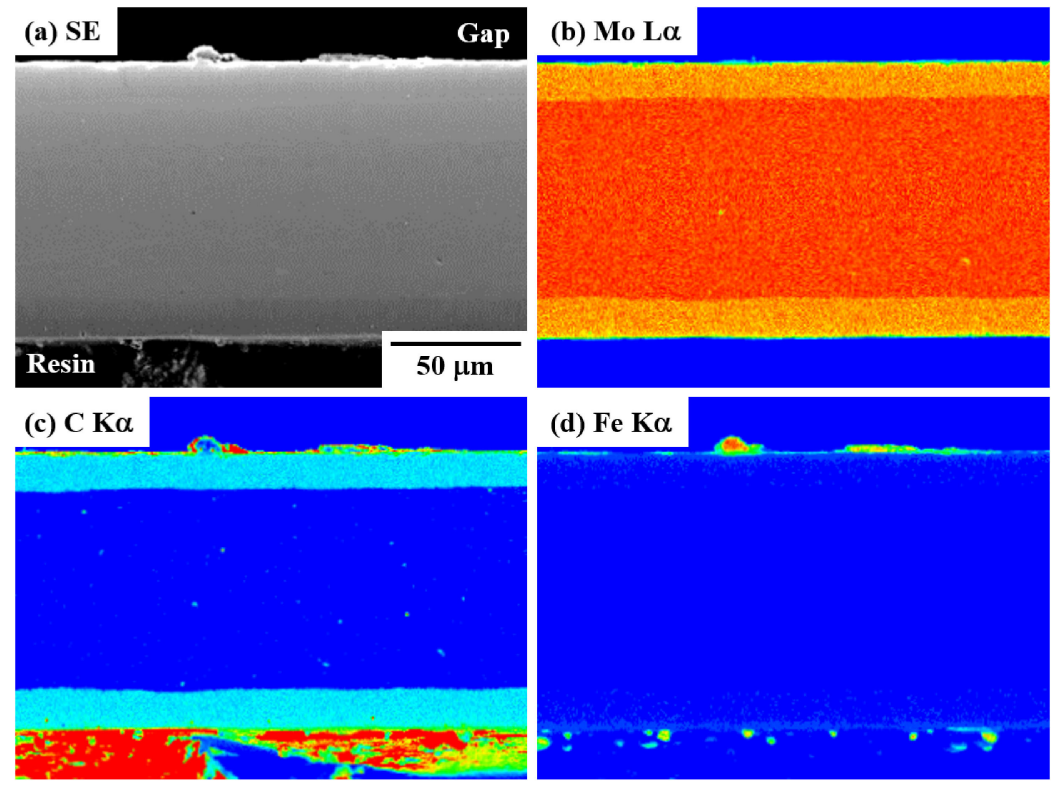

(d) $\mathrm{Fe} \mathrm{K} \alpha$
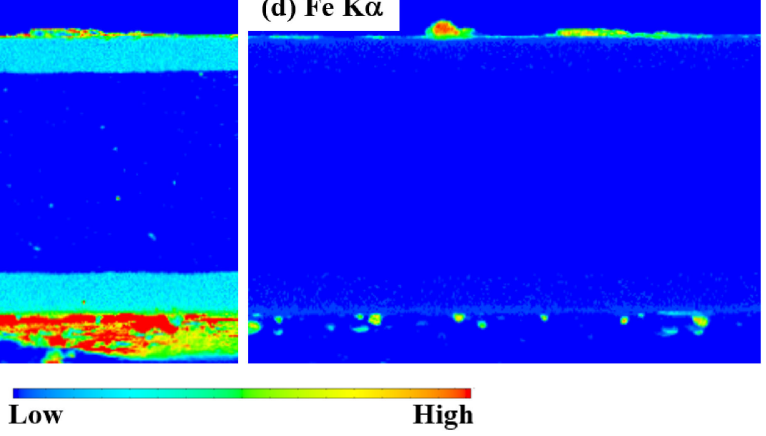

Fig. 4 Elemental mapping of a cross section of a molybdenum sheet heat-treated at $1273 \mathrm{~K}$ for $3.6 \mathrm{ks}$ in a nitrogen flow using a $4: 6: 2$ mixture of iron, graphite and alumina powders. 


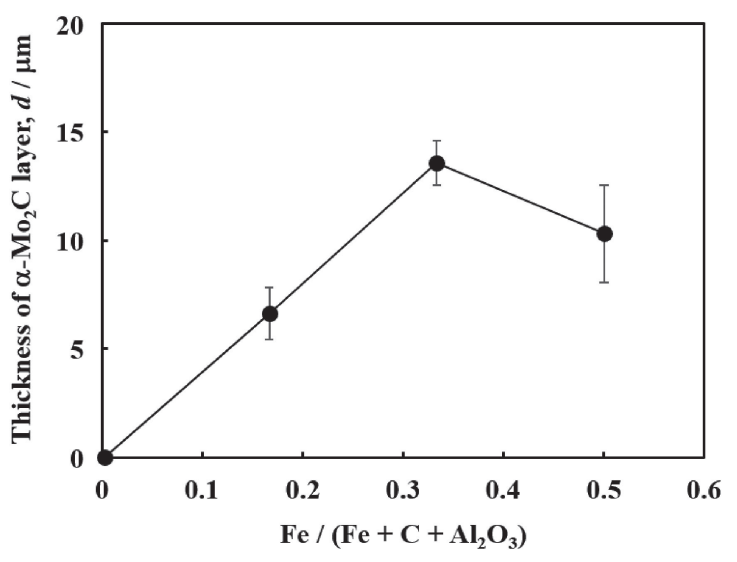

Fig. 5 Thickness of the $\alpha-\mathrm{Mo}_{2} \mathrm{C}$ layer formed on a molybdenum sheet heat-treated at $1273 \mathrm{~K}$ for $3.6 \mathrm{ks}$ in a nitrogen flow using various powder mixtures. The horizontal axis is the $\mathrm{Fe} /\left(\mathrm{Fe}+\mathrm{C}+\mathrm{Al}_{2} \mathrm{O}_{3}\right)$ ratio in Table 1 .

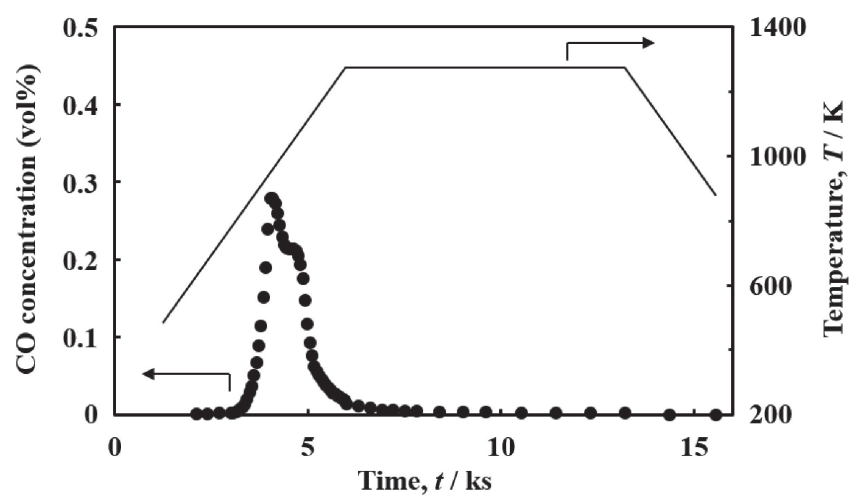

Fig. 6 Carbon monoxide (CO) gas concentration detected during IPP treatment at $1273 \mathrm{~K}$ for $7.2 \mathrm{ks}$ in a nitrogen flow using a 4:6:2 mixture of iron, graphite and alumina powders.

and a 4:6:2 mixture $\left[\mathrm{Fe} /\left(\mathrm{Fe}+\mathrm{C}+\mathrm{Al}_{2} \mathrm{O}_{3}\right)=0.33\right]$ led to the thickest layer. However, the thickness of the layer produced by using a 6:4:2 mixture $\left[\mathrm{Fe} /\left(\mathrm{Fe}+\mathrm{C}+\mathrm{Al}_{2} \mathrm{O}_{3}\right)=0.50\right]$ decreased because of a decrease in the graphite powder as a carbon source. Such changes were consistent with the results of the surface hardness shown in Fig. 2. This suggests that the degree of influence of the molybdenum substrate on the hardness values is dependent on the thickness of the $\alpha-\mathrm{Mo}_{2} \mathrm{C}$ layer formed on the substrate surface.

Figure 6 shows a measurement result of $\mathrm{CO}$ concentration detected during IPP treatment at $1273 \mathrm{~K}$ using a 4:6:2 mixture of iron, graphite and alumina powders. The holding time in this case was $7.2 \mathrm{ks}$. A peak for $\mathrm{CO}$ gas was observed in the vicinity of $950 \mathrm{~K}$ in the heating step, and then its concentration was retained at a low level. Such a result has been reported in our previous studies as a typical feature of IPP treatment. ${ }^{6,8,14)}$ It has also been known that $\mathrm{CO}$ is scarcely generated when a mixture of graphite and alumina powders is heated in a nitrogen flow. ${ }^{8)}$ The generation of $\mathrm{CO}$ indicates the chemical reaction between the carbon in the powder mixtures and residual oxygen in the electric furnace. Because $\mathrm{CO}$ is released with the nitrogen flow from the exhaust port of the furnace, oxygen in the furnace is probably expelled. Accordingly, the oxygen partial pressure should be low and an environment to make it easy for carbon to diffuse into molybdenum may be produced. Furthermore, the low
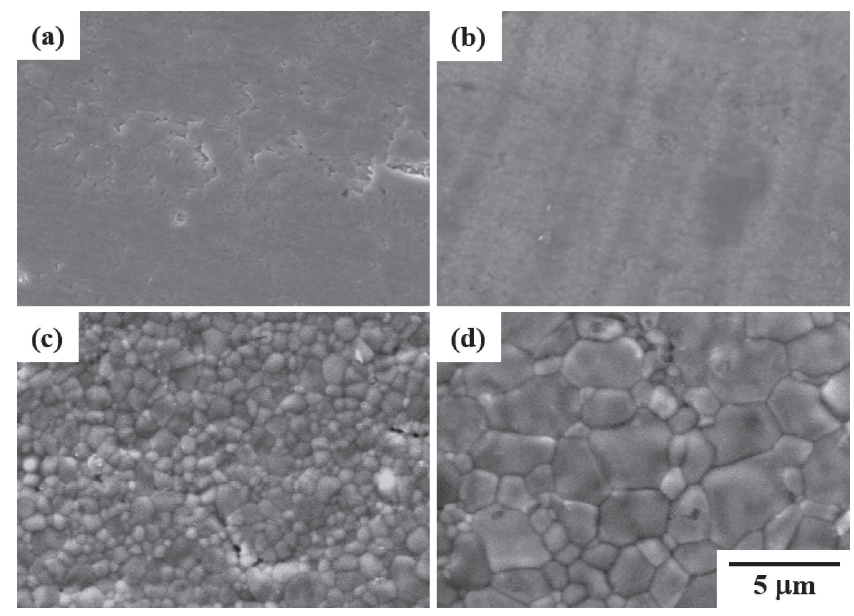

Fig. 7 SEM images of the surface of a molybdenum sheet heat-treated at (a) 1073 , (b) 1173 , (c) 1273 and (d) $1373 \mathrm{~K}$ for $3.6 \mathrm{ks}$ in a nitrogen flow using a 4:6:2 mixture of iron, graphite and alumina powders.

concentration of $\mathrm{CO}$ in the holding step means that the contribution of the gas to the formation of $\alpha-\mathrm{Mo}_{2} \mathrm{C}$ is small in contrast with carburization for surface hardening of steels. There is a possibility that carbon necessary for $\alpha-\mathrm{Mo}_{2} \mathrm{C}$ is directly supplied from mixtures of iron, graphite and alumina powders.

\subsection{Effects of the heating temperature and holding time}

The optimum powder for IPP treatment of molybdenum was determined to be a 4:6:2 mixture of iron, graphite and alumina powders. The molybdenum sheets were modified by using this mixture, and the effects of the heating temperature and holding time on the formation of $\alpha-\mathrm{Mo}_{2} \mathrm{C}$ was investigated.

Figure 7 shows SEM images of the surface of the molybdenum sheet heat-treated in the temperature range of $1073-1373 \mathrm{~K}$ for $3.6 \mathrm{ks}$ in a nitrogen flow using the $4: 6: 2$ mixture. At 1273 and $1373 \mathrm{~K}$, fine grains were observed on the surface and their size increased with an increase in the heating temperature. According to Figs. 1(c) and 3, they corresponded to the surface microstructures of the $\alpha-\mathrm{Mo}_{2} \mathrm{C}$ layer. On the other hand, the surfaces heat-treated at 1073 and $1173 \mathrm{~K}$ did not show a distinctive aspect. XRD patterns of these surfaces are shown in Fig. 8. At $1073 \mathrm{~K}$, there were small diffraction peaks for $\alpha-\mathrm{Mo}_{2} \mathrm{C}$ in the XRD pattern. In this case, the pattern was similar to that in Fig. 1(a), but an inhomogeneous layer with a thickness of about $1 \mu \mathrm{m}$ was observed.

The molybdenum sheets subjected to IPP treatment using the 4:6:2 mixture were cut in half, and their cross sections were observed. Figure 9 shows the relationship between the heating temperature, the holding time and the thickness of the $\alpha-\mathrm{Mo}_{2} \mathrm{C}$ layer. The horizontal axis is expressed as the square root of the holding time. In all heating temperatures, an increase in the layer thickness showed a linear relationship to the square root of the holding time. In addition, the thickness of the modified sheet, which was composed of the $\alpha-\mathrm{Mo}_{2} \mathrm{C}$ layer and the molybdenum substrate, was nearly the same as that of the untreated sheet. This means that the $\alpha-\mathrm{Mo}_{2} \mathrm{C}$ layer grows toward the inside of the molybdenum sheet. 


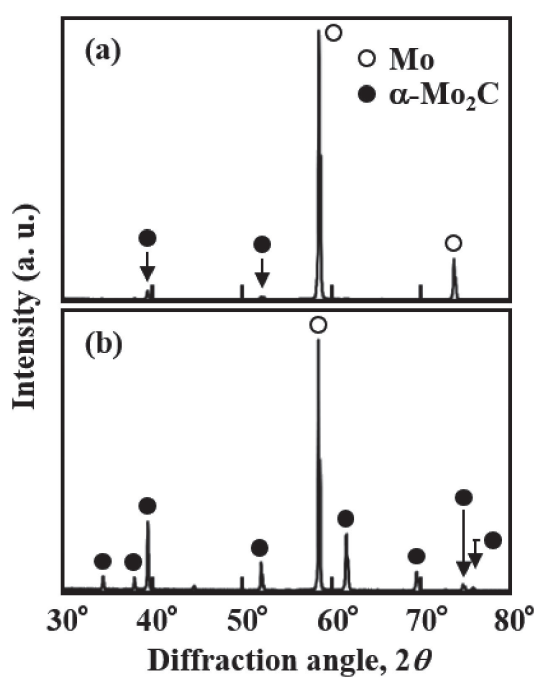

Fig. 8 XRD patterns of the surface of a molybdenum sheet heat-treated at (a) 1073 and (b) $1173 \mathrm{~K}$ for $3.6 \mathrm{ks}$ in a nitrogen flow using a 4:6:2 mixture of iron, graphite and alumina powders.

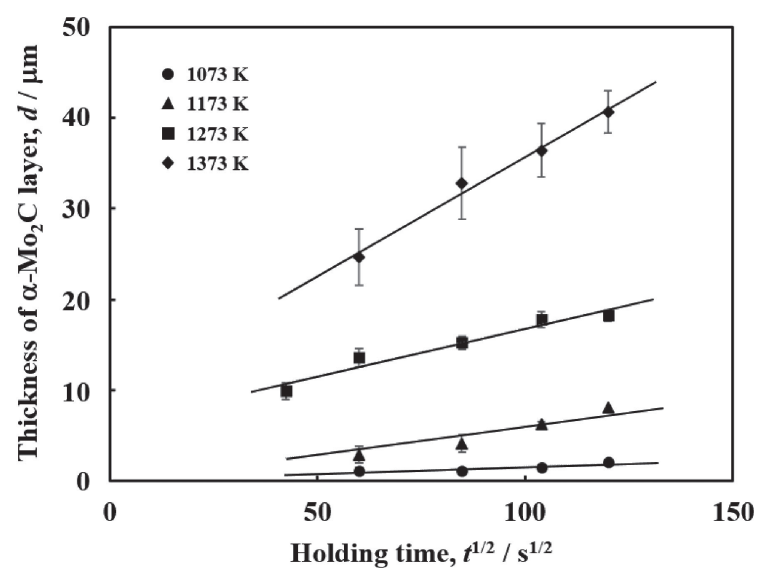

Fig. 9 Relationship between the holding time and the thickness of the $\alpha-\mathrm{Mo}_{2} \mathrm{C}$ layer formed on a molybdenum sheet heat-treated at various temperatures in a nitrogen flow using a 4:6:2 mixture of iron, graphite and alumina powders.

The activation energy for growth of the $\alpha-\mathrm{Mo}_{2} \mathrm{C}$ layer was calculated on the basis of Fig. 9, and the value was 220 $\mathrm{kJ} / \mathrm{mol}$. Morozumi et al. have reported that the activation energy for growth of a reaction layer consisting mainly of $\alpha-\mathrm{Mo}_{2} \mathrm{C}$, which is formed in molybdenum/carbon diffusion couples heat-treated at $1373-2173 \mathrm{~K}$ for up to $360 \mathrm{ks}$ in a vacuum, is $374 \mathrm{KJ} / \mathrm{mol}^{15)}$ Martinz and Prandini have also obtained $343 \mathrm{~kJ} / \mathrm{mol}$ for growth of an $\alpha-\mathrm{Mo}_{2} \mathrm{C}$ layer, when molybdenum immersed in a carbon-filled alumina crucible is heat-treated at $1523-1823 \mathrm{~K}$ for up to $36 \mathrm{ks}$ in a vacuum. ${ }^{9)}$ On the other hand, the value of $240 \mathrm{~kJ} / \mathrm{mol}$ has been reported by Isobe et al. ${ }^{16)}$ They have examined the growth of an $\alpha-\mathrm{Mo}_{2} \mathrm{C}$ layer formed in molybdenum/graphite diffusion couples heat-treated in the temperature range of 1173 $1373 \mathrm{~K}$. The value obtained in the present study was close to that reported by Isobe et al. The activation energy for growth of the $\alpha-\mathrm{Mo}_{2} \mathrm{C}$ layer seems to be influenced by the temperature range for evaluating the layer growth.

Furthermore, Isobe et al. have reported that the thickness of an $\alpha-\mathrm{Mo}_{2} \mathrm{C}$ layer was approximately $6 \mu \mathrm{m}$, when a

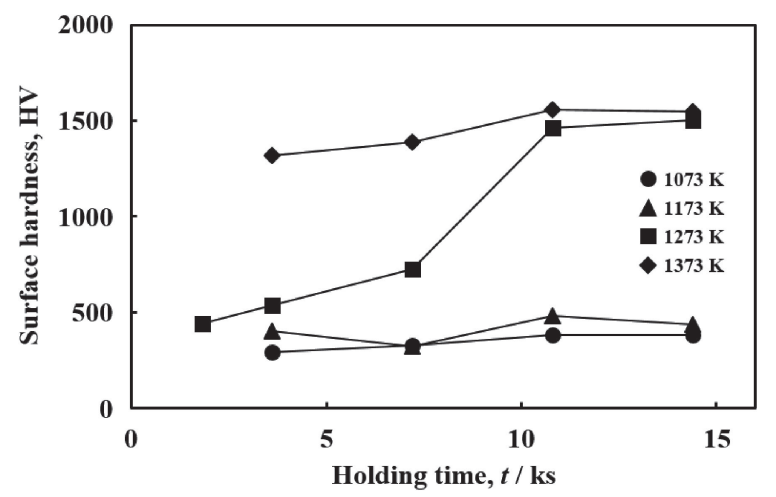

Fig. 10 Effects of the heating temperature and holding time on the surface hardness of a molybdenum sheet heat-treated in a nitrogen flow using a 4:6:2 mixture of iron, graphite and alumina powders.

graphite substrate coated with a CVD film of molybdenum was heat-treated at $1173 \mathrm{~K}$ for $360 \mathrm{ks}$ in a vacuum of $0.01 \mathrm{mPa} .{ }^{16)}$ In Fig. 9, the time required at $1173 \mathrm{~K}$ for forming the $\alpha-\mathrm{Mo}_{2} \mathrm{C}$ layer having the same thickness was about $10 \mathrm{ks}$. By comparing both cases, it is easy to understand the effectiveness of IPP treatment as a carburizing technique for molybdenum.

Figure 10 shows the effect of the holding time on the surface hardness of the molybdenum sheet heat-treated at various temperatures in a nitrogen flow using the 4:6:2 mixture. As described above, since a load of $2.94 \mathrm{~N}$ was applied in the hardness tests, the obtained values were affected by the molybdenum substrate. In other words, the influence of the thickness of the $\alpha-\mathrm{Mo}_{2} \mathrm{C}$ layer was reflected in the figure. In particular, a remarkable change in the surface hardness occurred at $1273 \mathrm{~K}$. The sheet covered with the $\alpha-\mathrm{Mo}_{2} \mathrm{C}$ layer with a thickness of at least about $20 \mu \mathrm{m}$ showed the highest surface hardness of approximately HV $=1500$.

\section{Conclusions}

Molybdenum sheets were embedded in mixtures of iron, graphite and alumina powders, and then heat-treated at 1073$1373 \mathrm{~K}$ for $1.8-14.4 \mathrm{ks}$ in a nitrogen flow. We call this process "iron-powder pack (IPP) treatment", and its effectiveness was discussed on the basis of the microstructures and hardness in the vicinity of the molybdenum surface. The main results are summarized as follows:

(1) An $\alpha-\mathrm{Mo}_{2} \mathrm{C}$ layer formed on the molybdenum surface by IPP treatment using the mixtures containing iron powder. The optimum volume ratio of iron, graphite and alumina powders was 4:6:2. When the molybdenum sheet was heat-treated at $1273 \mathrm{~K}$ for $3.6 \mathrm{ks}$ in a nitrogen flow using this mixture, it was covered with the $\alpha-\mathrm{Mo}_{2} \mathrm{C}$ layer with a thickness of approximately $14 \mu \mathrm{m}$.

(2) The thickness of the $\alpha-\mathrm{Mo}_{2} \mathrm{C}$ layer increased in proportion to the square root of the holding time. In addition, the layer grew toward the inside of the molybdenum via the diffusion of carbon from the powder mixture. The activation energy for growth of the layer was $220 \mathrm{~kJ} / \mathrm{mol}$.

(3) Vickers hardness tests (test load: $2.94 \mathrm{~N}$ ) was conducted on the molybdenum surface modified by IPP treatment. 
The surface covered with the thick $\alpha-\mathrm{Mo}_{2} \mathrm{C}$ layer showed a high hardness value of about 1500 .

\section{Acknowledgements}

The authors would like to express their appreciation to Y. Hara for his kind assistance in the experiments. This work was supported by ISIJ Research Promotion Grant and JSPS KAKENHI Grant Numbers JP15K06509 and JP19K05045.

\section{REFERENCES}

1) T. Bell, H.W. Bergmann, J. Lanagan, P.H. Morton and A.M. Staines: Surf. Eng. 2 (1986) 133-143.

2) E. Roliński: Mater. Sci. Eng. A 108 (1989) 37-44.

3) N. Kanayama, Y. Horie and T. Tanabe: J. Surf. Finish. Soc. Jpn. 44 (1993) 683-686.

4) T. Wierzchoń and A. Fleszar: Surf. Coat. Technol. 96 (1997) 205-209.

5) T. Kim, Y. Park and M. Wey: Mater. Sci. Eng. A 361 (2003) 275-280.

6) Y. Morizono, Y. Kawano, S. Tsurekawa and T. Yamamuro: Mater.
Trans. 54 (2013) 1454-1459.

7) Y. Morizono, S. Tsurekawa, T. Yamamuro, S. Yoshida and Y. Kawano: Mater. Trans. 58 (2017) 600-605.

8) Y. Morizono, S. Tsurekawa and T. Yamamuro: ISIJ Int. 58 (2018) 2110-2116.

9) H. Martinz and K. Prandini: Int. J. Refr. Metals Hard Mater. 12 (19931994) 179-186.

10) M. Nagae, A. Kunisada, J. Takada, Y. Hiraoka, Y. Takemoto, M. Hida and H. Kuwahara: J. Jpn. Soc. Powder Powder Metall. 45 (1998) 189_ 194.

11) T. Hoshika, Y. Hiraoka, M. Nagae and J. Takada: J. Jpn. Soc. Powder Powder Metall. 49 (2002) 32-36.

12) Metals Data Book, ed. by The Japan Institute of Metals and Materials, (Maruzen Co., Ltd., Tokyo, 1993) pp. 650-651.

13) Metals Data Book, ed. by The Japan Institute of Metals and Materials, (Maruzen Co., Ltd., Tokyo, 1993) p. 504.

14) Y. Morizono, S. Tsurekawa and T. Yamamuro: Tetsu-to-Hagané 98 (2012) 476-481.

15) S. Morozumi, M. Kikuchi, S. Sugai and M. Hayashi: J. Japan Inst. Metals 44 (1980) 1404-1413.

16) Y. Isobe, P. Son and M. Miyake: J. Less-Common Met. 147 (1989) 261-268. 